\title{
Pharmacogenomics and migraine: possible implications
}

\author{
Peer Tfelt-Hansen · Kim Brøsen
}

Received: 19 February 2007 / Accepted: 12 December 2007/Published online: 24 January 2008

(C) Springer-Verlag 2008

\begin{abstract}
Pharmacogenomics is the science about how inherited factors influence the effects of drugs. Drug response is always a result of mutually interacting genes with important modifications from environmental and constitutional factors. Based on the genetic variability of pharmacokinetic and in some cases pharmacodynamic variability we mention possible implications for the acute and preventive treatment of migraine. Pharmacogenomics will most likely in the future be one part of our therapeutic armamentarium and will provide a stronger scientific basis for optimizing drug therapy on the basis of each patient's genetic constitution.
\end{abstract}

Keywords Migraine - Pharmacogenomics .

Pharmacokinetics · Pharmacodynamics

\section{Introduction}

The human genome consists of approximately three billion base pairs, and the number of coding sequences ("genes") ranges from 20 to 25,000 [1]. Single nucleotide polymorphisms or SNPs (pronounced "snips") are DNA sequence variations that occur when a single nucleotide $(\mathrm{A}, \mathrm{T}, \mathrm{C}$, or $\mathrm{G})$ in the genome sequence is altered in at least $1 \%$ of the population. SNPs, which make up about $90 \%$ of all human

P. Tfelt-Hansen $(\square)$

Danish Headache Centre, Department of Neurology,

University of Copenhagen, Glostrup Hospital,

Glostrup 2600, Denmark

e-mail: tfelt@inet.uni2.dk

K. Brøsen

Institute of Public Health, Clinical Pharmacology,

University of Southern Denmark, Odense, Denmark genetic variation, occur every 100-300 bases along the 3-billion-base human genome. SNPs can occur in both coding (gene) and noncoding regions of the genome. Many SNPs have no effect on cell function, but some could predispose people to disease or influence their response to a drug. Pharmacogenomics is the science about how inherited factors influence the effects of drugs [2]. It is a new science about how the systematic identification of all the human genes, their products, interindividual variation, intraindividual variation in expression and function over time may be used both to predict the right treatment in individual patients and to design new drugs.

Drug response is always to some extent determined by genetic factors. It is never determined by a single gene alone or by a group of genes. Drug response is always a result of mutually interacting genes with important modifications from environmental and constitutional factors.

Genotyping before treatment is of possible value if drug response mainly is determined by a single or just a few genes characterized for all clinically relevant SNPs, and when all clinically relevant environmental and constitutional influences are known and measurable both when treatment is initiated and during treatment.

The classical phenotype definition of genetic polymorphism is a phenotypic trait that exists in the population in at least two phenotypes (and presumably in at least two genotypes) the rarest of whom exist in say $1 \%$ of the population.

In the past, pharmacogenetics mostly dealt with genetic polymorphism in drug metabolism. The main enzyme system responsible for drug metabolism is the cytochrome P450 (CYP) enzyme system. In humans there are 57 CYP genes and 33 pseudogenes. They are organized into 18 families and 42 subfamilies. The CYP enzymes that metabolize drugs belong to families 1, 2 and 3 . 
The pharmacogenomic research ultimately aims of developing better and safer drugs and/or better and safer use of currently available drugs.

Migraine can be regarded as an episodic-chronic disorder [3] and in the treatment of migraine one should consider treatment of the migraine attacks and in many cases also preventive treatment. Therefore the possible implications of pharmacogenomics will be dealt with in the following separately for acute and preventive migraine treatment. In each of these sections the possible pharmacokinetic and pharmacodynamic implications will be described.

Very little has been achieved until the recent demonstration in cluster headache that the response to triptans is related to polymorphism in the $\mathrm{G}$ protein $\beta 3$ [4].

In 2001 it was stated: as migraine has been demonstrated to have a strong, but complex, genetic component, pharmacogenetics bears great promise in providing new targets for drug development and optimization of individual specific therapy [5]. Better, preferably prophylactic, treatment of migraine patients is desired because the drugs now used are not effective in all patients, allow recurrence of the headache in a high percentage of patients and sometimes have severe adverse events [5].

\section{Acute migraine treatment}

The anti-migraine, specific triptans, 5- $\mathrm{HT}_{1 \mathrm{~B} / 1 \mathrm{D}}$ receptor agonists, are generally regarded, as very effective acute migraine drugs [6]. This fact, however, is not always evident in current randomised clinical trials with oral triptans [7-9]. One could argue that this is so because only the most severely afflicted patients participate in these randomised clinical trials. However, in migraine patients with infrequent attacks recruited by general practitioners and by advertisement the results are quite similar [10].

It was recently stated that many patients have no response to triptans and complete pain relief is the exception rather than the rule [11]. How high is then the maximum effect of triptans? After subcutaneous naratrip$\tan 10 \mathrm{mg}$ the pain-free response was $87 \%$ [12, 13]. Hence, with parenteral naratriptan one gets near the maximum for pain-free.

Pharmacogenomics and pharmacokinetics

Eletriptan is metabolised by CYP3A4 and the oral bioavailability (OBA) is 50\%. Sumatriptan (OBA 14\%), rizatriptan (OBA 40\%), almotriptan (OBA 80\%) are all metabolised by monoamine oxidase (MAO)-A [9, 14, 15]. Zolmitriptan (OBA 39\%) is metabolised by CYP 1A2 and the active metabolite $183 \mathrm{C} 91$ by MAO-A [16]. Naratriptan (OBA $74 \%$ ) is excreted by the kidney and metabolism represents only a minor route of elimination of the drug [17].

The $C_{\max }$ after oral $200 \mathrm{mg}$ sumatriptan varied from 52 to $227 \mathrm{ng} / \mathrm{ml}$ in healthy volunteers [18]. In migraine patients outside attacks the $2 \mathrm{~h}$ plasma levels of zolmitriptan varied from 3 to $27 \mathrm{ng} / \mathrm{ml}$ and during attacks the plasma levels varied from 0 to $15 \mathrm{ng} / \mathrm{ml}$ after zolmitriptan $10 \mathrm{mg}$ [19]. Such large variability in plasma levels suggests heterogeneity in the metabolism in the liver most likely due to heterogeneity of MOA-A and CYP1A2.

\section{Clinical comments}

Ideally, one could try whether the migraine patient respond to subcutaneous sumatriptan $6 \mathrm{mg}$, the currently most effective available treatment $[8,9]$. If the patient respond to subcutaneous sumatriptan one could then because can be inconvenient and because of the high cost of the subcutaneous sumatriptan (35 Euro per injection) try oral administration of a triptan. In theory genotyping of the patient may be useful, if the patient is not responding, and depending on the triptan in question it could in theory be genotyping of MAO-A, CYP $1 \mathrm{~A} 2$ and CYP3A4 (see above). However, genotyping for these three enzymes is not relevant in clinical practice because the prediction of the phenotype is poor.

A CGRP antagonist BIBN079BS was effective when given intravenously [11] and CGRP antagonists are now being developed for oral use. The CGRP antagonist MK-0974 $300 \mathrm{mg}$ (68\%) was superior to placebo (46\%) for headache relief in a phase II study [20]. The pharmacokinetic profile of MK-0974 and variability of its metabolic pass way is currently unknown.

Pharmacogenomics and pharmacodynamics

Freedom of pain after $2 \mathrm{~h}$ is the currently suggested primary efficacy parameter in randomised, clinical trials in migraine [21]. Treatment with an oral triptan results in pain-free responses from 30 to $40 \%$ of the patients in randomised, clinical trials when the headaches are moderate or severe [7]. When the migraine attacks are treated in the mild phase of headache the $2 \mathrm{~h}$ pain-free responder rate increases considerably. Thus, the pain-free response was $43 \%$ after zolmitriptan $2.5 \mathrm{mg}$ [22], 51-66\% after sumatriptan 50-100 mg [23, 24], and 70\% after rizatriptan $10 \mathrm{mg}[25]$.

For subcutaneous naratripan the dose-response curve was established in one early study in the development 
programme of the drug, see Fig. 1 [12]. The mere fact that a dose-response could be established in this relatively small study ( $n=34-69$ per dose) and that a high maximum response of $87 \%$ (95\% confidence intervals: $78-93 \%$ )[12, 13] was found suggest homogeneity in the pharmacodynamic response to naratriptan.

The pain-free response was lower for sumatriptan: $33 \%$ (95\% confidence intervals: -15 to $-51 \%$ ) [12]. The high maximum effect for naratriptan $10 \mathrm{mg}, 87 \%$ pain-free [12], could be inherent to this drug because it is $2-3$ times more potent than sumatriptan at the $5-\mathrm{HT}_{1 \mathrm{~B} / 1 \mathrm{D}}$ receptor in some animal models relevant to migraine $[26,27]$ but, at present, this remains a matter of speculation.

The CGRP receptor on human middle meningeal artery is CGRP (1) [28]. There is no information about possible genetic heterogeneity of this receptor in man. In coronary arteries there is heterogeneity of the CGRP receptor CGRP (1), CGRP (2) and unknown [29].

One large study in cluster headache was recently published [4]. In 231 cluster headache patients the GNB3 genotype and allele frequency were indistinguishable from other cross-sectional German samples [4]. A total of 180 patients used a triptan, of whom $71 \%$ reported treatment success. The adjusted odds ratio for treatment response to triptans for heterozygotous carriers of the GNB3 825T allele was 2.96 (95\% confidence interval 1.34-6.56; $P=0.0074$ ) versus carriers of the 825CC genotype [4]. The C825TC polymorphism had a positive predictive value for triptan response of 0.82 and a negative predictive value of 0.35 . The C825T polymorphism has been associated with an enhanced signal transduction via $G$ protein-coupled receptors [4]. The same polymorphism has been associated with hypertension [30, 31], with the response to

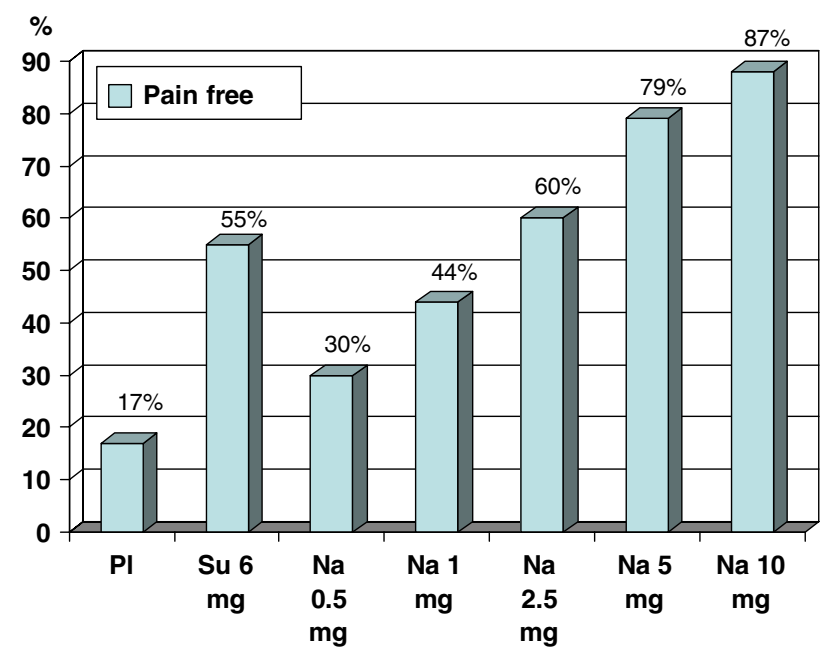

Fig. 1 Pain-free response after $2 \mathrm{~h}$ for placebo $(n=63)$, and subcutaneous naratriptan (Na) $(0.5 \mathrm{mg}(n=69), 1 \mathrm{mg}(n=55)$, $2.5 \mathrm{mg}(n=42), 5 \mathrm{mg}(n=34), 10 \mathrm{mg}(n=34)$, and sumatriptam $6 \mathrm{mg}(n=47)[12]$ antidepressant [32] and with the venous response to nitroglycerin [33].

In another study with same patient population it was found that the G1246A polymorphism in the hypocretin receptor 2 gene was not associated with treatment response [34].

Previously, no evidence for involvement of the 5-HT1F receptor gene in the response to sumatriptan in migraine patients was found [35]. Similarly, in the same migraine patient population there was no association of drug response and 5-HT1B receptor polymorphism [36]. A recent study found no evidence that variants F124C and A-161T of the 5-HT receptor are major determinants in the clinical response to sumatriptan [37]. One recent study suggested that the DRD2/NcoI allele may be considered a susceptibility factor heralding a good response to oral rizatriptan [38].

\section{Clinical comments}

The results for $\mathrm{G}$ protein $\beta 3$ polymorphism in cluster headache [4] should be investigated in migraine patients. If there is an association between the response in migraine patients to triptans and the polymorphism then genotyping for this gene will be an option in the future.

There is heterogeneity of the $5-\mathrm{HT}_{1 \mathrm{~B}}$ receptor but this was not linked to treatment response

\section{Preventive migraine treatment}

The majority of drugs currently used in migraine prevention were not developed for migraine prophylaxis [39-42]. The serotonin antagonists methysergide and pizotifen were developed 40-50 years ago for migraine prophylaxis [43]. Preventive drugs for migraine, beta-blockers, serotonin antagonists, calcium blockers, antiepileptics, NSAIDs, and antidepressants, are not universally effective. The responder rates (a 50\% decrease in incidence) range from 40 to $50 \%$ [39-42, 44]. Ideally, preventive treatment should results in no or one attack per month [43] but this cannot be obtained with current unspecific therapy. In the future, one can hope that migraine specific preventive therapy will be developed.

Pharmacogenetics and pharmacokinetics

The two beta-blockers propranolol and metoprolol have very varied pharmacokinetics, in both cases most likely due to differences in the first-passage effect and metabolic excretion by CYP enzymes. The recommended doses vary 
considerable, for example in essential tremor: $60-800 \mathrm{mg}$ propranolol daily [45]. In migraine the recommended doses are 40-320 mg propranolol and 50-200 mg metoprolol [39].

Propranolol is highly lipophilic and it is well absorbed. Most of the drug is metabolized by the liver during its first passage through the portal circulation resulting in $25 \%$ oral bioavailability [39]. There is great interindividual variation in the presystemic clearance of propranolol resulting in enormous variability in plasma concentration after oral administration of the drug (approximately 20-fold). Propranolol is extensively metabolized and one of the products of hepatic metabolism is 4-hydroxypropranolol, which posses some $\beta$-blocking effect.

Propranolol is metabolised mainly by the P450 isozyme CYP1A2 [46]. CYP1A2 displays considerable interindividual variability, and this is due mainly to genetic factors [46]. So far no SNP or haplotype in the CYP1A2 has yet been identified that can unequivocally be used to predict the metabolic phenotype in any individual patient [47]. CYP1A2 and CYP2D6 hydroxylate propranolol and they exhibit racial differences [48]. The genotype responsible for the more than 60 -fold interindividual differences in human hepatic CYP1A2 constitutive expression is not known [47]. There is a racial difference in the expression of CYP1A2 [49].

Metoprolol is well absorbed but there is considerable first-pass metabolism resulting in about $40 \%$ oral bioavailability [40]. Plasma-concentrations of the drug vary widely (up to 17-fold). Metoprolol is metabolised by CYP2D6 and there is a 30-fold difference between the highest and lowest clearance values [50] and a 30-fold variability in AUC for the extensive metabolisers of metoprolol [51]. For CYP2D6 there is genetic polymorphism with autosomal recessive heritage. Seven percent of white Caucasians and $1-2 \%$ of Blacks and Orientals [39, 52] do not express this enzyme and are "poor metabolisers". There is a pronounced allelic heterogeneity: approximately 80 known variants, mainly in the form of single nucleotide polymorphisms's. CYP2D6*3, *4 and *5 together predict about $90 \%$ of poor metabolisers [53].

Results in cardiovascular patients suggested that pharmacogenomic measures could be used to design more individualized metoprolol dosage regimen for patients [50]. In hypertensive patients, however, there was no association between variable pharmacokinetics or CYP2D6 genotypes and beta-blocker-induced adverse events or efficacy [51].

Topiramate is not extensively predominately metabolised and $50 \%$ is excreted by the kidneys as unmetabolised drug [54]. Valproate is metabolised in the liver mainly by glucuronidation but also by oxidation by several CYP [54]. The calcium entry blocker flunarizine is metabolised by CYP2D [55]. Methysergide is a prodrug and is metabolised with demethylation in the liver during the first-passage to an active metabolite methylergometrine [56]. After oral administration the AUC is 10 times greater for methylergometrine than for methysergide [56]. Amitriptyline is metabolised by $\mathrm{N}$-demethylation by to nortiptyline by CYP2C19, CYP1A2 and CYP3A4 [53].

\section{Clinical comments}

Preventive treatment in migraine is generally started with low doses that are then, if necessary, increased over weeks or months [39], the "start low go slow" dictum. With genotyping of relevant metabolic enzymes one can probably in an advance design more individualized drug dosage regimen for patients. Whether such regimens results in better treatment depends on whether there is an association between plasma levels and drug response. So far, this has only been investigated in a small $(n=17)$ open study for propranolol where no correlation was found [57].

For valproate determination of plasma levels is a routine and one normally tend to titrate the dose to the levels used in epilepsy.

Amitriptyline is $\mathrm{N}$-demethylated to nortriptyline via CYP1A2, CYP2C19 and CYP3A4 and 10-hydroxylated by CYP2D6 [53]. All four enzymes are under genetic control, but there is not a single genotype test, which predicts the plasma levels of amitriptyline and nortriptyline.

\section{Pharmacogenomics and pharmacodynamics}

A variety of genetic and nongenetic factors determine $\beta_{1}$ blocker response [58]. Besides inherited differences in the metabolism and disposition of drugs, gene polymorphisms in the targets of drug therapy, for example receptors, can have a significant influence on the efficacy and toxicity of medications [59]. As mentioned above, there was no association between variable pharmacokinetics or CYP2D6 genotypes and beta-blocker-induced adverse events or efficacy [51]. In contrast, polymorphisms of the $\beta_{1}$-adrenoceptor determined the response to metoprolol in hypertension in two studies [58,59].

The mode of action of $\beta$-blockers in migraine is unknown but is most likely via an effect on the brain, probably on the central catecholaminergic system, as indicated by the effect of $\beta$-blockers on contingent negative variation in migraineurs $[39,60]$.

\section{Clinical comments}

If the effect of $\beta$-blockers in migraine is exerted by an effect on the $\beta_{1}$-receptor genotyping for this receptor could 
possibly in advance predict responders and nonresponders confer the results in hypertension [58, 59].

For the other preventive medications in migraine, serotonin antagonists, calcium entry blockers, antiepileptic drugs, antidepressants, their mode of action in migraine is unknown [40-43] and one can thus not for the moment suggest what genes one should type in order to predict response.

\section{Final comments}

Until now attempts to use pharmacogenomics in migraine have been few and most have fail. In the future this will be different. Pharmacogenomics will most likely in the future be one part of our therapeutic armamentarium. Before use of medication we will in some cases ask for genotyping of relevant pharmacokinetic or pharmacodynamic genotypes and then tailor the drug regimen to the individual patient. The need for genotyping is most likely greatest in preventive treatment also in order to minimize the adverse events, which frequently occur with this treatment [39-42, 44]. Pharmacogenomics will thus provide a stronger scientific basis for optimizing drug therapy on the basis of each patient's genetic constitution [61] and will be an integral determination of drug therapy [2]. This is most likely to be the case when new migraine-specific, better preventive drugs based on knowledge of the pathophysiology of migraine have been developed.

Conflicts of interest None.

\section{References}

1. http://www.ornl.gov/sci/techresources/Human_Genome/home.shtml

2. Giacomini KM, Brett CM, Altman RB, Benowitz WL, Dolan ME, Flockhart DA et al, for the Pharmacogenetic Research Network (2007) The pharmacogenetics research network: from SNP to clinical drug response. Clin Pharmacol Ther 81:328-345

3. Lipton RB, Bigal ME, Stewart WF (2005) Clinical trials of acute treatment for migraine including multiple attacks studies of pain, disability, and health-related quality of life. Neurology 65(Suppl 4):S50-S58

4. Schürks M, Kurth T, Stude P, Rimmbach C, de Jesus J, Jonjic M, Diener H-C, Rosskopf D (2007) G protein $\beta 3$ polymorphism and triptan response in cluster headache. Clin Pharmacol Ther 82:396-401

5. Ophoff RA, van den Maagdenberg AM, Roon KI, Ferrari MD, Frants RR (2001) The impact of pharmacogenetics for migraine. Eur J Pharmacol 413:1-10

6. Lipton RB, Bigal ME, Goadsby PJ (2004) Double-blind clinical trials of oral triptans versus other classes of acute migraine medication-a review. Cephalalgia 24:321-322

7. Ferrari MD, Roon KI, Lipton RB, Goadsby PJ (2001) Oral triptans (serotonin $5-\mathrm{HT}_{1 \mathrm{~B} / ! \mathrm{D}}$ agonists) in acute migraine: a metaanalysis of 53 trials. Lancet 358:1668-1675
8. Tfelt-Hansen P, De Vries P, Saxena PR (2000) Triptans in migraine. A comparative review of pharmacology, pharmacokinetics and efficacy. Drugs 60:1259-1287

9. Saxena PR, Tfelt-Hansen P (2006) Triptans, 5HT1B/1D agonists in the acute treatment of migraine. In: Olesen J, Goadsby PJ, Ramadan NM, Tfelt-Hansen P, Welch KMA (eds) The headaches, 3rd edn. Lippincott, Philadelphia, pp 469-503

10. Tfelt-Hansen P, Bach F, Daugaard D, Tsiropoulos I, Riddersholm B (2006) Treatment with sumatriptan $50 \mathrm{mg}$ in the mild phase of migraine attacks in patients with infrequent attacks. A randomised, double-blind, placebo-controlled study. J Headache Pain 7:389-394

11. Olesen J, Diener H-C, Husstedt IW, Goadsby PJ, Hall D, Meier U, Pollentier S, Lesko LM, for the BIBN 4096 BS Clinical Proof of Concept Study Group (2004) Calcitonin gene-related peptide receptor antagonist BIBN $4096 \mathrm{BS}$ for the acute treatment of migraine. N Engl J Med 350:1104-1110

12. Dahlöf C, Hogenhuis L, Olesen J, Petit H, Ribbat J, Schoenen J et al (1998) Early clinical experience with subcutaneous naratriptan in the acute treatment of migraine: a dose-ranging study. Eur J Neurol 5:469-477

13. Tfelt-Hansen $P$. The maximum effect of triptans in migraine? A comment. Cephalalgia (in press)

14. Wellington K, Plosker GL (2002) Rizatriptan: an update of its use in the management of migraine. Drugs 62:1539-1574

15. Keam SJ, Goa KL, Figgitt DP (2002) Almotriptan: a review of its use in migraine. Drugs 62:387-414

16. Goadsby PJ, Yates R (2006) Zolmitriptan intranasal: a review of pharmacokinetics and clinical efficacy. Headache 46:138-149

17. US package insert for naratriptan

18. Lacey LF, Hussey EK, Fowler PA (1995) Single dose pharmacokinetics of sumatriptan in healthy volunteers. Eur J Clin Pharmacol 47:543-548

19. Thomsen LL, Dixon R, Lassen LH, Giboens M, Langemark M, Bendtsen L, Daugaard D, Olesen J (1996) 311C90 (zolmitriptan), a novel centrally and peripheral acting oral 5-hydroxytryptamine1D agonist: a comparison of its absorption during a migraine attack and in a migraine-free period. Cephalalgia 16:270-275

20. Ho TW, Mannix LK, Fan X, Assaid C, Furtek C, Jones C, Lines CJ, Rapoport AM, On behalf of the MK-0974 Protocol 004 study group (2007) Randomized controlled trial of an oral CGRP antagonist, MK-0974, in the acute treatment of migraine. Neurology [Epub ahead of print]

21. International Headache Society Clinical Trial Subcommittee (2000) Guidelines for controlled trials of drugs in migraine, 2nd edn. Cephalalgia 20:765-786

22. Klapper J, Lucas C, Rosjo O, Charlesworth B, ZODIAC Study Group (2004) Benefits of treating highly disabled migraine patients with zolmitriptan in while pain is mild. Cephalalgia 24:918-924

23. Nett R, Landy S, Schackelford S, Richardson MS, Ames M, Lener M (2003) Pain-free efficacy after treatment with sumatriptan in the mild phase of menstrually associated migraine. Obstet Gynecol 102:835-842

24. Winner P, Landy S, Richardson M, Ames M (2005) Early intervention in migraine with sumatriptan tablets 50 vs $100 \mathrm{mg}$ : a pooled analysis of data from six trials. Clin Ther 27:1785-1794

25. Mathew NT, Kailasam J, Meadors I (2004) Early treatment of migraine with rizatriptan: a placebo-controlled study. Headache 44:669-673

26. Connor HE, Feniuk W, Beattie DT, North PC, Oxford AW, Saynor DA, Humphrey PPA (1997) Naratriptan: biological profile in animal models relevant to migraine. Cephalalgia 17:145152

27. Humphrey PP (2007) The discovery of a new drug class for the acute treatment of migraine. Headache 47(Suppl 1):S10-S19 
28. Gupta S, Mehrotra S, Avezaat CJ, Villalon CM, Saxena PR, Massenvandenbrink A (2006) Characterisation of CGRP receptors in the human isolated middle meningeal artery. Life Sci 79:265-271

29. Gupta S, Mehrotra S, Villalon CM,Garreld IM, de Vries R, van Kats JP et al (2006) Characterisation of CGRP receptors in human and pocine isolated coronary arteries: evidence for receptor heterogeneity. Eur J Pharmacol 530:107-116

30. Siffert W, Rosskopf D, Siffert G, Busch S, Moritz A, Erbel R et al (1998) Association of human $G$ protein beta3 subunit variant with hypertension. Nat Genet 18:45-48

31. Rosskopf D, Schurks M, Rimmbach C, Shäfers R (2007) Genetic of arterial hypertension and hypotension. Naunyn Schmiedebergs Arch Pharmacol 374:429-469

32. Serreti A, Artioli P, Quartesan R (2005) Pharmacogenomics in the treatment of depression: pharmacodynamic studies. Phamacokinet Genomics 15:61-67

33. Mitchell A, Bührman S, Seifert A, Nürnberger J, Wenzel RR, Siffert W et al (2003) Venous response to nitroglycerin is enhanced in young, healthy carriers of the $825 \mathrm{~T}$ allele of the $\mathrm{G}$ protein $\beta 3$ subunit gene (GNB3). Clin Pharmacol Ther 74:499_ 504

34. Schürks M, Kurth T, Geiassler, Tessmann G, Diener H-C, Rosskopf D (2007) The G1246A polymorphism in the hypocretin receptor 2 gene is not associated with treatment response in cluster headache. Cephalalgia 27:363-367

35. Massen VanDenBrink A, Vergouwe MN, Ophoff RA, Naylor SL, Dauwerse HG, Saxena PR, Ferrari MD, Frants RR (1998) Chromosomal localization of the 5-HT1F receptor gene: no evidence for involvement in response to sumatriptan in migraine patients. Am J Med Genet 77:415-420

36. Massen VanDenBrink A, Vergouwe MN, Ophoff RA, Saxena PR, Ferrari MD, Frants RR (1998) 5-HT1B receptor polymorphism and clinical response to sumatriptan. Headache 38:288291

37. Mehrotra S, Vanmolkot KR, Frants RR, van den Haagdenberg AM, Ferrari MD, Maassevandenbrink A (2007) The Phe-124-Cys and A-161 T variants of the human 5-HT (1B) receptor gene are not major determinant of the clinical response to sumatriptan. Headache 47:711-716

38. Asuni C, Cherchi A, Congui D, Piccardi MP, Del Zompo M, Stochino ME (2007) Association study between clinical response to mrizatriptan and some candidate genes. J Headache Pain 8:185-189

39. Tfelt-Hansen $\mathrm{P}$, Rolan $\mathrm{P}$ (2006) $\beta$-Adrenoceptor blocking drugs in migraine prophylaxis. In: Olesen J,Goadsby PJ, Ramadan NM, Tfelt-Hansen P, Welch KMA (eds) The headaches, 3rd edn. Lippincott, Philadelphia, pp 519-528

40. Toda N, Tfelt-Hansen P (2006) Calcium antagonists in migraine prophylaxis. In: Olesen J, Goadsby PJ, Ramadan NM, TfeltHansen P, Welch KMA (eds) The headaches, 3rd edn. Lippincott, Philadelphia, pp 539-544

41. Silberstein SD, Tfelt-Hansen P (2006) Antiepileptic drugs in migraine prophylaxis In: Olesen J, Tfelt-Hansen P, Goadsby PJ, Ramadan NM, Welch KMA (eds) The headaches, 3rd edn. Lippincott, Philadelphia, pp 545-551

42. Evers S, Mylecharane EJ (2006) Nonsteriodal anti-inflammatory and miscellaneous drugs in migraine prophylaxis. In: Olesen $\mathrm{J}$, Goadsby PJ, Ramadan NM, Tfelt-Hansen P, Welch KMA (eds) The headaches, 3rd edn. Lippincott, Philadelphia, pp 553-565

43. Tfelt-Hansen P. Stricter success criteria. Qualitative and quantitative end points. Acute versus preventive trials In: Olesen J, Ramadan NM (eds) Innovative drug development in headache. International Headache Research Seminar, March 2007 (in press)
44. Tfelt-Hansen P, Saxena PR (2006) Antiserotonin drugs in migraine prophylaxis. In: Olesen J, Goadsby PJ, Ramadan NM, Tfelt-Hansen P, Welch KMA (eds) The headaches, 3rd edn. Lippincott, Philadelphia, pp 529-537

45. Benito-Leon J, Louis ED (2007) Clinical update: diagnosis and treatment of essential tremor. Lancet 369:1152-1154

46. Rasmussen BB, Brix TH, Kyvik KO, Brosen K (2002) The interindividual differences in the 3-demethylation of caffeine alias CYP1A2 is determined by both genetic and environmental factors. Pharmacogenetics 12:473-478

47. Jiang Z, Dragin N, Jorge-Nebert LF, Martin MV, Guengerich FP, Aklillu E et al (2006) Search for an association between the human CYP1A2 genotype and CYP1A2 metabolic phenotype. Pharmacogenet Genomics 16:359-367

48. Johnson JA, Herring VL, Wolfe MS, Relling MV (2000) CYP1A2 and CYP2D4 4-hydroxylate propranolol and both exhibit racial differences. J Pharmacol Exp Ther 294:1099-1105

49. Ghobti R, Christensen M, Roh HK, Ingelman-sundberg M, Aklillu E, Bertilsson L (2007) Comparison of CYP1A2 genetic polymorphisms, enzyme activity and genotype-phenotype relationship in Swedes and Koreans. Eur J Clin Pharmacol 63:537546

50. Ismail R, Teh LK (2006) The relevance of CYP 2D6 genetic polymorphism on chronic metoprolol in cardiovascular patients. $\mathrm{J}$ Clin Pharmacol Ther 31:99-109

51. Zineh J, BeitelShees AL, Gaedigk A, Walker JR, Pauly DF, Eberst K et al (2004) Pharmacokinetics and CYP2D6 genotypes do not predict metoprolol adverse events or efficacy in hypertension. Clin Pharmacol Ther 76:536-44

52. Johnson JA, Burlew BS (1996) Metoprolol metabolism via cytochrome P4502D6 in ethnic populations. Drug Metab Dispos 24:350-355

53. Brøsen K (2004) Some aspect of genetic polymorphism in the biotransformation of antidepressant. Therapie 59:5-12

54. Patsalos PN (2005) Properties of antiepileptic drugs used in the treatment of generalized epiplepsies. Epilepsia 46(Suppl 9):140148

55. Todd PA, Benfield P (1989) Flunarizine. A reappraisal of its pharmacological properties and therapeutic use in neurological disorders. Drugs 38:481-499

56. Bredberg U, Eyjolfsdottir GS, Paalzow L, Tfelt-Hansen P, TfeltHansen V (1986) Pharmacokinetics of methysergide and its metabolite methylergometrine in man. Eur J Clin Pharmacol 30:75-77

57. Cortelli P, Sacquegna T, Albani F, Baldrati A, D’Alessandro R, Baruzi A et al (1985) Propranolol plasma levels and relief of migraine: relationship between plasma propranolol and 4-hydroxypropranolol concentrations and clinical effects. Arch Neurol 42:46-48

58. Johnson JA, Zineh I, Bucket BJ, McCorray SP, Yarandi HN, Pauly DF (2003) Beta 1-adrenergic receptor polymorphisms and antihypertensive response to metopolol. Clin Pharmacol Ther 74:44-52

59. Liu J, Liu Z-Q, Yu B-N, Xu F-H, Mo W, Zhou G et al (2006) $\beta_{1^{-}}$ Adrenoceptor receptor polymorphisms influence the response to metoprolol monotherapy in patients with essential hypertension. Clin Pharmacol Ther 80:23-32

60. Schoenen J, Maertens de Noordhout A, Timsit- Berthier M, Timsit M (1986) Contingent negative variation and efficacy of beta-blocking agents in migraine. Cephalalgia 6:229-233

61. Evans WE, Relling MV (1999) Pharmacogenomics: translating functional genomics into rational therapy. Science 286:487-491 